Resumo

\title{
Nível de Hidratação e Reposição Hídrica dos Atletas da Seleção Brasileira Militar de Futebol: Comportamento Semelhante nas Diferentes Posições da Equipe
}

Thiago Carneiro Santana Bsci, Miriam Raquel Mainenti PhD

Introdução: Esse estudo centra-se na análise da hidratação de jogadores de futebol e reposição hídrica durante um treinamento da modalidade, comparando as posições dos jogadores em campo e verificando possíveis alterações no nível de desempenho desses atletas numa situação de jogo.

Objetivo: Verificar se o nível de hidratação e reposição hídrica tem relação com a posição do atleta no campo de jogo.

Métodos: Para cumprir esse objetivo, foi feita uma análise do nível de hidratação através da massa corporal total (MCT), da densidade (refratômetro analógico) e coloração da urina (escala de Armstrong) antes e após o treino. Também foi registrada a reposição hídrica a partir da quantidade de água restante em uma garrafa de 1,5 litros. Foram verificadas as alterações advindas com o treino na amostra total (teste de Wilcoxon), bem como, comparando as modificações por posição do atleta em campo através (Kruskal-Wallis). Adicionalmente, o coeficiente de Sperman foi utilizado para verificação do grau de correlação entre a reposição hídrica e as alterações das três variáveis de hidratação. Foram significativos os valores de $p \leq 0,05$.

Resultados: Considerando a amostra total, foi observada uma redução estatisticamente significativa da MCT e uma tendência de aumento $(\mathrm{p}=0,08)$ dos escores da escala da coloração da urina. Não foi observada modificação significativa na densidade da urina. Comparando as posições em campo, não foi observada diferença entre as variações (pós - pré) de MCT ( $\mathrm{p}=0,367$ ), densidade $(p=0,588)$ e coloração da urina $(p=0,305)$. Em relação à reposição hídrica, também não foi observada diferença $(p=0,627)$. A variável reposição hídrica apresentou correlação regular positiva com MCT e negativa com densidade da urina.

Conclusão: Os dados analisados mostram que não há relação entre a posição no campo de jogo com o seu nível de hidratação e reposição hídrica durante um treino físico-técnico. 